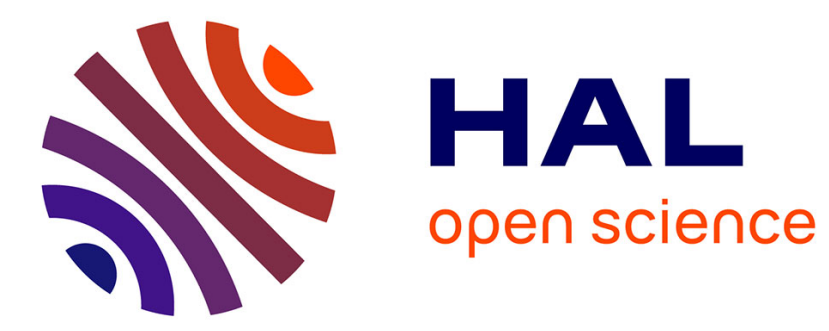

\title{
STABLE NECKS ON METAL TIPS
}

\author{
M. Drechsler, S. Ramdani, Alain Claverie, A. Maas
}

\section{To cite this version:}

M. Drechsler, S. Ramdani, Alain Claverie, A. Maas. STABLE NECKS ON METAL TIPS. Journal de Physique Colloques, 1987, 48 (C6), pp.C6-209-C6-214. 10.1051/jphyscol:1987634 . jpa-00226838

\section{HAL Id: jpa-00226838 https://hal.science/jpa-00226838}

Submitted on 1 Jan 1987

HAL is a multi-disciplinary open access archive for the deposit and dissemination of scientific research documents, whether they are published or not. The documents may come from teaching and research institutions in France or abroad, or from public or private research centers.
L'archive ouverte pluridisciplinaire HAL, est destinée au dépôt et à la diffusion de documents scientifiques de niveau recherche, publiés ou non, émanant des établissements d'enseignement et de recherche français ou étrangers, des laboratoires publics ou privés. 
M. Drechsler, S. Ramdani, A. Claverie and A. Maas ${ }^{\star}$

CRMC2-CNRS, Campus de Luminy case 913, 13288 Marseille cedex 09, France *CNRS, Laboratoire d'Optique Electronique, 31055 Toulouse, France

$\star \star A$.G. Festkörper-Oberflächen, Universität Bonn, 5300 Bonn, F.R.G.

\begin{abstract}
ABSTRnCT : On a metal tip ( $W, \mathrm{N1}, \mathrm{Au}, \mathrm{Cu}$ ) heated in an electron microscope (SER) a formation of atable neclis is observed. As this does not agree with the theory, experiments are made for claxification. In situ electron microscopy (Tin, syen, HoLS) show the existence of graphitised surface layers, which suxprisingly remain atable up to near the melting point. Theme layers hinder a complete separation of a solid metal drop from the tip end. On the basis of this result spectacular tip and neck shape changes are explainable as an ostwald ripening.
\end{abstract}

\title{
1. IATPRODOCTION
}

When a nearly cylindrical motal tip is heated in the vacurm of an electron microscope. apectacular relatively etable necks are formed $/ 1 / 12 /$. An this phencenenon is not underatood, which hinders the use of tips for surface and materials science studies, we have now studied the stable neck phenowenon in sowe detail and describe the result in thie paper.

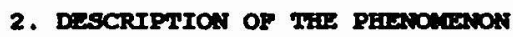

2.1. Theoretical basis.

wich is the moxphological evolution of a heated solid metal in vacuum ? answer is given on the basis of the kinisT-EINSTEIN equation of matter transport in the case of wetal tipe by the calculated resulte of MICBOIs and MurIIs $/ 1 /$. Depending on the tip cone angle $\alpha$ two dowains of tip evolution excet (1) for cone angles $\alpha>30$ the tip end radius $r$ increases continuously and a measurement of $r$ as a function of time has been often used to determine surface self-diffueion coefficients of wetals /2/. (2) For wallex cone angles $(\alpha<30)$ the calculation prealcts a formation of a $t$ ip neck of decreasing dianeter until a solid drop is separated from the tip end. An exanple of such an evolution is shown in fig. 1 . This second evolution is the basis of the phenomenon debcribed in this paper.

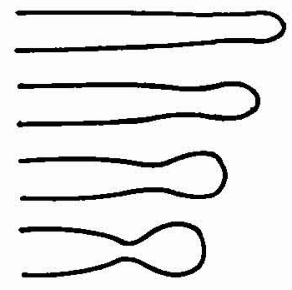

Fig. 1 - Calculated shape evolution of a mated tip by cap1liarity Induced surface self-alffurion traneport $/ 1 / 3 / 3$. IIp cone angle 20 .

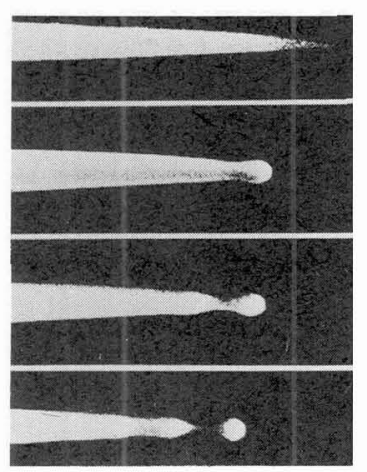

0 min

$9 \min$

$60 \min$

$135 \mathrm{~min}$

Fig. 2 - smape evolution of a single cryotal tungsten tip vieualized by a rcanning electron microecope $/ 3 /$. $T=2300 \mathrm{~K}, \alpha \sim 30$. 
2.2. Stable neck on a single crystal tip.

The experimental evolution of a single cryatal tip is show in fig. 2. At first $\nabla$ iew calculated and experimental evolutions seems to agree. However there is an important discrepancy in the time dependence of this evolution. The calculation predicts that the time of the existence of a small neck is small compared to the time of the formation of the neck but this is opposite to the experimental result. So the fundamental problem exist : why are thin necks so otable?

\subsection{Stable necks on a polycristalline tip.}

The necks on polycrystalline tips are somewhat alfferent to those on single crystal tips. A typical experimental result is schematized in fig. 3. (gee also fig. 10 ). Firstly the usual system of irregulax grain boundaries is transformed by boundary migrations in a system of "bamboo" boundaxies (fig. 3 a and b). Boundary grooves and necks are formed at these boundaries (fig. 3 b and c) $/ 4 /$.

Pig. 3d 1lluetrates again the main problem studied in this paper, while the calculation predicts a grain or solid drop separation from the tip, the experiment show in nearly all cases an appearence of a stable neck. What is the reason for this discrepancy ?

a)

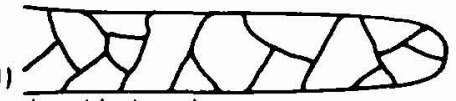

tip with irregular boundaries

b)

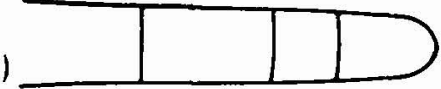

"bamboo" boundaries are formed

Pig. 3 - scheme of the formation of stable necks on a polycrystalline tip ( $t$ ip radius increase is neglected).

2.4. Cylinarical neaks.

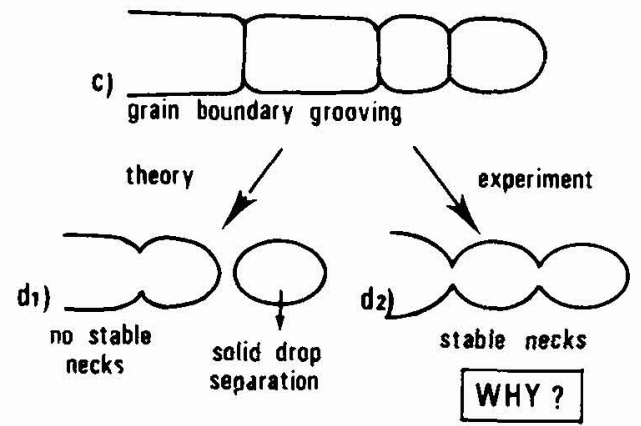

A special type of (relatively) stable necks are cylindrical necks. An example is ahown in $\mathrm{fig}$. 4. The alameter of the neck is about $400 \mathrm{~A}$. It 18 ourprising that a neck with such a great surface to volume ratio is formed.

Fig. - Formation of a cylindrical stable neck on $\mathrm{Ki}$ tip $/ 3 /$ heated ( $1250 \mathrm{~K}$ ) in the absence of electron impact.

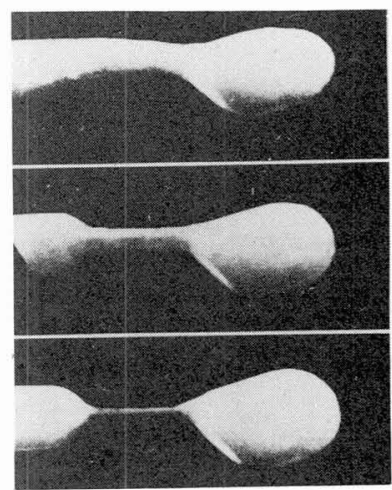

0 min

$3 \min$

$6 \mathrm{~min}$ 


\section{THE FINDING THAY STABLE NECKS YUST BE RELATED TO SURPACE LAYERS}

In order to obtain better information on atable necks we ataxted to study the prablem by transwigsion (Instead of scanning) electron microscopy. Used was a $100 \mathrm{kV}$ TEM (Philipe) with a heating chamber up to $1500 \mathrm{~K} / 5 /$ and the $3 \mathrm{kV}$ microscope of Toulouse with a heating chamber up to $1000 \mathrm{~K}$. In situ video registration was used in poth cases. The advantages of uaing a Twr are: (1) The much better resolution ( $5 \AA$ ). (2) The vigualization of surface layers $/ 6 /$ (fig. B). (3) The possibility to abtain information on impurities by dark field diffraction imaging. Impurities can originate from the reaidual gas in the microscope of $\sim 10^{-6}$ Torr (typically $\mathrm{B}_{2} \mathrm{O}, \mathrm{O}_{2}, \mathrm{~N}_{2}, \mathrm{H}_{2}$, hydrocarbons as $\mathrm{CH}_{4}, \ldots$ ). In fact the dark field study indicates and localizes an impurity (fig. 5 and 6 ). The surprising result is that the neck region is sometimes completely tal (Cu) free (fig. 5 and 6 ). Bright field imaging show that the whole tip surface is often covered with a surface layer (fig. 8) $/ 6 /$. The measured layer thickness 18 in the range between zero and $\sim 300 \mathrm{~A} / 6 /$. A correct layer substance analysis was made by STH electron enexgy losg spectroscopy (with the help of $\mathrm{kr}$. Fourmeaux, Toulouse). The generalized result is that the substance of the layers is graphitized caxbon. This is surprising because the well known graphitized layers in Twi and sen microscopy are known to be detached from the specimen surface at temperatures in the order of $300 \mathrm{C}$ (also confirmed by our abservations) while other layers were stable up to about $1000 \mathrm{C}$ and some probably up to $20000 \mathrm{C}$. A general conclusion of these results is that graphitized layers of very different stability exist. If a layer is more or less stable seems to depend (1) on the layer preparation and ( 2 ) on the specimen geometry (plane f1lm, tip, supported particles).

Fig. 5 - stable neck on a cu tip during in situ heating $(1200 \mathrm{~K})$ and video registration. Tra dark field image. The bright lines indicate a noncopper surface layer. Neck diameter $\sim 400 \mathrm{~h}$.

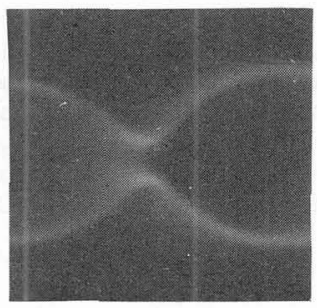

PIg. 6 - stable neck as in fig. 5. The neck appears bright that is free of copper.

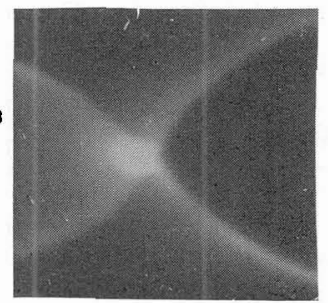

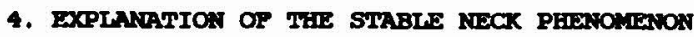

The stable neck model which agrees best with the experimental results is schematized in fig. 7. Pig. 7a shows a low angle tip after some surface gelf-diffusion. At $\sim 10^{-6}$ Torr and elevated temperature a graphitized surface layer of increasing thickness is formed. In detail, the hydrocarbons of the gas are adsorbed and desorbed on the tip surface, where a submonolayer of adsorbed hydrocarbons is formed. These are cracked by the high temperature, by the impinging electrons ( $100 \mathrm{kV}$ ) or by both. The hydrogen desorbs wile the carbon effects the growth of the graphitized layer. The experience show that the presence of the graphitized layex has often (surprisingly) little influence on the $\mathrm{Cu}$ surface diffusion transport along the $\mathrm{Cu}$ surface. In former interpretation of stable neck micrographs (as in fig. 10) it was assumed that the solid metal drop is not sepaxated from the tip shank. This interpretation must be 
reviged. The drop is mostly separated from the tip metal but atill hold by the nonmetallic layer (fig. 7c, fig. 6 and 8 ).

Fig. 7 - Explanation of the formation of a stable neck on a single crystal tip (gee text). a)

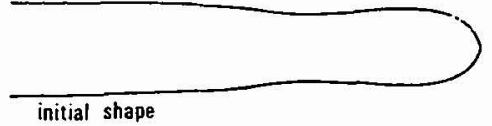

b)

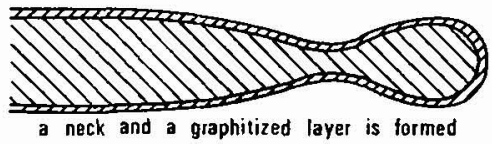

c)

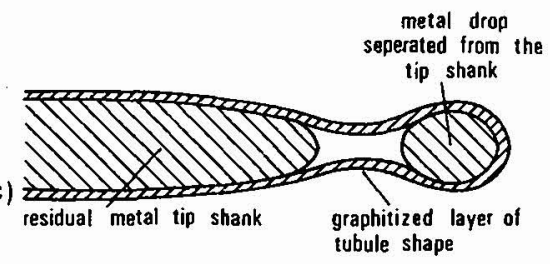

Pig. 8 - TEM ( $3 \times 10^{6} \mathrm{v}$ ) micxograph of a cu tip after heating during observation ( $800 \mathrm{C}$ for $\sim 20 \mathrm{~min}$ ). The solid cu drop ( $1.5 \mathrm{~mm}$ ) is separated from the metal shank and is only hold by the layer $(\sim$ $10^{3}$ A thick) which has a tubule shape at the neck. STEW-EELS analysis has shown that the bright appearing layer is graphitized carbon. The few gmall dark point in the layer are isolated very small cu crystallites.

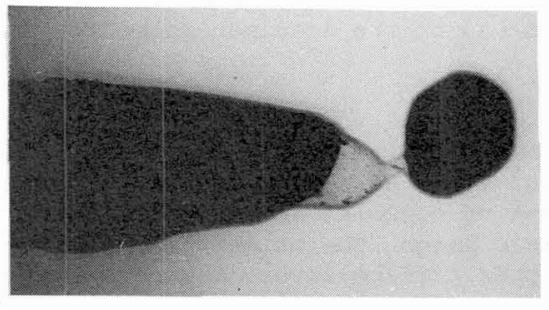

\section{A MODEL FOR THE FORIMATION OF CYLINDRICAL NECKS}

Why stable necks evolute sometimes to filiform necks (fig. 3) must be explained too. When the metal inside a neck ( $\mathrm{fig}$. 9a) is transported to the metal dxop or the tip shank a special vacuum space is formed ( $f 1 g$. 9b). The residual layer has a shape similar to a hollow double cone. Such a cone seems to be submitted to a driving force which tends to reduce the cone diameters (xeduction of the surface area). The hypothesis is that this cone can not resist to this force because ( 1 ) experiments show that such layers are very flexible (adaptation to support shape changes) and (2) the tiny lamelias of a graphitized layer should be easily displacable at high temperatures in lamella directions. Consequentiy the cone diameters should decrease, the lamellas may become more slightly curved and the layex thickness may increase somewhat. But this process must be limited because tre increasing curvature causes an increasing counter force. The state of minimum free energy formed should be a tubule of a limit diameter.

\section{UNSTABILITIES OP STABLE NECKS}

Stable necks are only relatively stable. In fact necks and tips show slow but spectacular shape variations. An example $/ 3 /$ is shown in fig. 10. Formerly it was supposed that such shape changes are perhaps caused by thermo-diffusion. Though thermo-diffusion may play a role, it geems not be a dominant role. The finding of the exiatence of the graphitized layers opens a new way to explain the myaterious ungtabilities.

The new hypothesis is that the oisappearence of stable necks is a apecial type of ostwald ripening. The ripening of spherical metal crystals is schematized in fig. 11a and $b$. Surface diffusion effects a transport of metal atoms from the small to the 
greater crystal, wich reduces the total metal surface area and the total fxee energy of the system. In the case of a tip with a stable neck (fig. 11 and d) the metal atoms migrate also to surface regions of greater burface radil so that the free energy of the oystem is reduced (the surface free enexgy of the graphitized layer is very small and can be neglected in the energy balance for aimplification).

Fig. 9 - Explanation of the formation of a filiform neck. a)

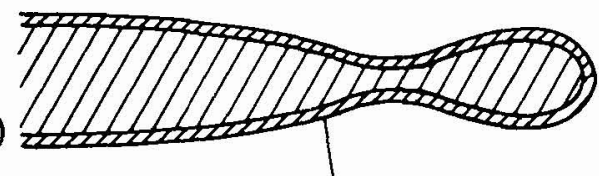

b)

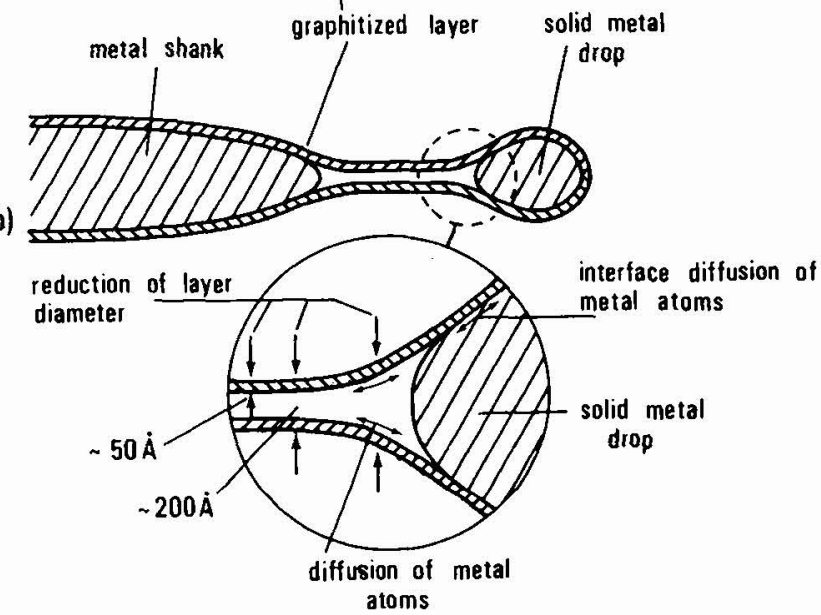

An analysis of micrographs series as that of fig. 10 show that the total metal surface area is continuously decreasing with time in all cases atudied so far. This is a strong argument to assume that the described ostwald ripening hypothesis is correct. Fesidual paxts of graphitized layex are not visible in the swi micrographs of fig. 10, but found in analogous Tux experiments with Cu tips.

P19. 10 - Disappearence of a solid drop with a atable neck ( $w, 2600 \mathrm{~K}$ ).

\section{Drscussios}

The explanation of the stable neck phenomena presented here is preliminaxy and need to be confirmed. It may be also desirable to study the stable necks in more detail in a quantitative mannex. 

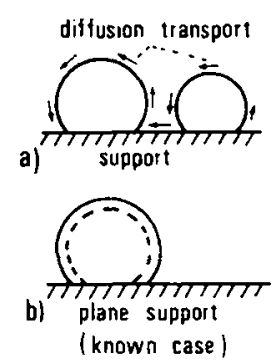

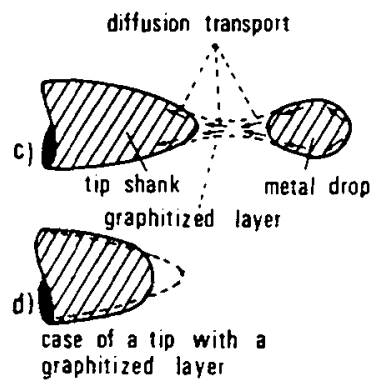

11g. 11 - scheme of the disappearence of a crystal by ostwald ripening on a plane eupport ( $a$ and $b$ ) and on a tip with a graphitized layex ( $c$ and a). The arrows indicate the alffusion trangport alrection.

\section{Conclustons}

(1) The formation of etable necks on metal tipe 18 a consequence of an existence of graphitized aurface layexs.

(2) Besides the known graphitized layers formed on electron microscope epecimens (and detached above $\sim 3000 \mathrm{C}$ ) exist others wich are stable up to $~ 20000 \mathrm{C}$ ).

(3) a stable neck 18 formed by a capiliarity induced seperation of a solid metal axop fron the tip but both remain hold together by the tubule graphitised 1 ayer.

(4) vatal atows alffuse easily along (1) the interface metal-graphitized layex and (2)

the Inner alce of the tubule layer.

(5) Solla dxops and atable neaks disappeax on long term by ostwald ripening.

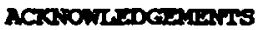

The authors 11ke to thank Nx. R. Fourmaax, Toulouse, Eaboratoire d'Optique Electronique du CaRs, for the analysis of the layer subtance.

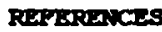

/1/ F.A. Nichols and W.W. Jullins , J. Appl. Physics 36 ( 1965 ) 1826

/2/ V.T. Binh, A. Piquet, H. Roux, R. Uzan, U, Drechaler : surface Sci. 25 (1971) 348 /3/ H. prechsler, A. Piquet, V.T. Binh and R. Usan, in structure et proprictes dea surfaces des solides, Coll. Int. du Cars, Paris 1970, P. 293 and suxface Sc1. 14 (1969) 457

/4/ V.T. Binh, M. Chaudiex, J.C. Couturier, R, Uzan and Y. Drechelex \& Surface sci. 57 (1976) 184

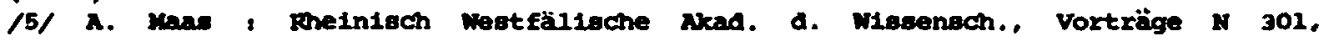
Mestdeutecher Vexlag, Dieseloore 1981, 51-124

/6/ $\mathrm{x}$. Drechsler, $\mathrm{s}$. Raviant and $\mathrm{A}$. vaas, paper accepted by surface sc1. 